\title{
RELIABILITY ANALYSIS \& PREDICTION OF MEAN TIME BETWEEN FAILURE OF FLIGHT DATA RECORDER
}

\author{
Suneel Kr Srivastava ${ }^{1}$, A K Chauhan ${ }^{2}$ \\ ${ }^{I}$ Dy. General Manager (D) Avionics Division, Korwa \\ ${ }^{2}$ A K Chauhan, Assistant Professor, KNIT, Sultanpur
}

\begin{abstract}
Flight data recorders also known as Black Box are used on military \& civil aircraft to record the parameters of flight duration. It provides the data for post flight analysis and analysis for investigation, if there is any accident or incident happened during flight. Criticality of application of this unit requires data to be available for post-accident analysis through Ground Replay Equipment to ascertain the cause of accident; hence there is a requirement to have a reliable product. Also Flight Data Recorders are used as Health Monitoring device for the Sensors data / Engine performance and analysis of flown Flight envelope for Pilots briefing \& de-briefing. Flight Data Recorders perform two operations during its functioning:
\end{abstract}

- Acquisition of data

- $\quad$ Recording of data in non-protected memory as well as in crash protected memory.

Prediction using MIL-HDBK-217F assumes a serial relationship between parts of the system, in which failure of any part constitutes system failure. The model assumes that:

- $\quad$ All parts are in constant failure rate proportion of their lifetime.

- Infant mortalities have been removed by component screening, electrical test, burn-in etc., and

- Wear-out has not been reached.

"Reliability Analysis \& Prediction of Mean Time between Failures (MTBF) of Flight Data Recorder" concludes that Failure Rate of the system works out to be 197.92 Failures $/ 10^{6}$ Hrs. i.e. Mean Time Between Failure of 5052.5hrs.

\section{INTRODUCTION}

This paper envisages the results of reliability prediction to be performed on Flight data Recorder. This reliability prediction is to be performed under Air force Inhabited Fighter Environment i.e. for airborne application.

Reliability prediction is an essential need in Military electronic systems. It is a means of reducing the cost from the factory, where rework of defective components adds a non-productive overhead expense. MIL-HDBK-217F[1] handbook was referred to perform this analysis.

MTBF prediction has many applications in the design and development process, including substantiating quantitative design requirements, identifying reliability drivers, making MTBF comparisons with competitive products, selecting warranty periods, advertising and marketing. It provides guidance, relative to expected inherent reliability of a given design

\section{OBJECTIVES}

Objectives of this analysis are to estimate the long-term "Flight Data Recorder" reliability using a recognized technique, specifically MIL-HDBK-217F [1] and it includes obtaining qualitative design information as applicable.
The objectives are as follows.

- Obtain feasibility evaluation

- Identify potential problems of design

- Identify those components with high operating stress

- Identify component application errors

- Provide MTBF figure of the system and subassemblies

- Obtain reliability improvement recommendations as needed to achieve long-term trouble free performance

\section{SPECIFICATIONS [2]}

FDR is designed to record 25 hours of Aircraft Data \& 2 hours of Audio (2-channel) during flight for crash or incident investigation. Apart from having advantage of reliability and large data storage capacity

\section{Data Acquisition Capabilities}

\section{External Parameters}

i. Analog Signal

Total Analog channels $=16$

Presently used channels $=14$

Spare channels $=2$ 
ii. Discrete Signal

Total Discrete channels $=24$

Presently used channels $=21$

Spare channels $=3$

(8 Discrete are as 0V/OC \&16 Discrete are as 28V/OC)

iii. Frequency Signal

Total Frequency channels $=4$

Presently used channels $=3$

Spare channels $=1$

iv. ARINC 429

Total ARINC 429 channels $=16$

Presently used channels $=7$

Spare channels $=9$

v. Audio Signal

Number of Channel $=2$

Recording Duration $=2 \mathrm{hrs}$

\section{SYSTEM ARCHITECTURE}

Flight data Recorder consists of two units as shown in Fig-1. These units are:

\section{- Data Acquisition Unit}

Protected memory Module

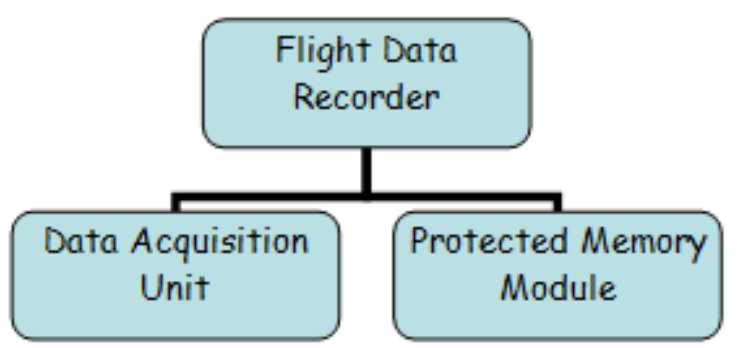

Fig 1

\subsection{Data Acquisition Unit}

Data Acquisition Unit is made of different modules (Fig-2) which include:

(i) Mother Board

(ii) Power Supply Module

(iii) Processor Board

(iv) ARINC \& Synchro Board

(v) Discrete Board

(vi) Analog Board

(vii) Audio Board

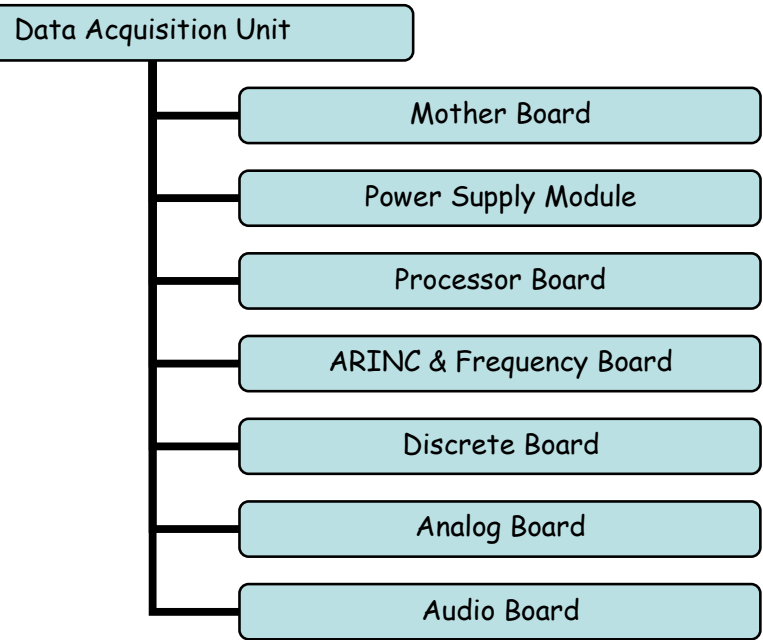

Fig-2

\subsection{Protected Memory Module}

PMM is a bought out assembly shown in Fig-3. It is composed of Memory Module having 384 MB Flash memories, buffers \& associated electronic circuits. The crash proof housing is made of high strength Titanium Alloy casting having thermal protection.

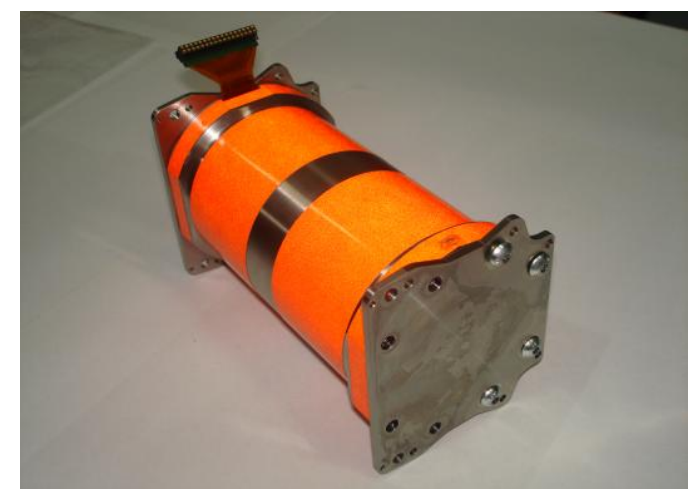

Fig-3

\section{PHYSICAL CHARACTERISTICS}

(i) Envelope dimensions

Length $320 \mathrm{~mm}$ Max

Width $124 \mathrm{~mm}$ Max

Height 194 mm Max

(ii) Weight

The overall weight of FDR shall not be more than 9 $\mathrm{Kg}$.

\section{ENVIRONMENTAL SPECIFICATIONS}

As per MIL STD 810D, MIL STD 704D, MIL STD 461C

\section{ASSUMPTIONS FOR RELIABILITY}

\section{ANALYSIS \& PREDICTION [3] [4] [5]}

Prediction Model used for prediction of reliability is Part Stress Method using MIL-HDBK-217F[1] 
The model assumes:

A serial relationship Reliability Block Model between parts of the system, in which failure of any part constitutes system failure

All parts are in constant failure rate proportion of their lifetime.

Infant mortalities have been removed by component screening, electrical test, burn-in etc., and

Wear-out has not been reached.

\section{Operating Environment}

All parts reliability models include the effect of environment stresses through Environmental factor $\pi \mathrm{E}$. This environmental factor is quantified within each part failure rate model.

Reliability Prediction has been performed using Airborne, Inhabited, and Fighter aircraft environment based on the operation of "Flight Data Recorder" system.

\section{Temperature}

Reliability Prediction has been performed on "Flight Data Recorder" system operating at $65 \mathrm{oC} \&$ storage temperature at $85 \mathrm{oC}$.

\section{CALCUlation OF FAILURE RATE FOR}

\section{RELIABILITY ANALYSIS \& PREDICTION}

Failure Rate of parts / components were calculated for prediction of reliability as per Part Stress Method using MIL-HDBK-217F[1] as follows :

- Component Level

- $\quad$ Module Level

- System Level

As per assumption, all parts are in constant failure rate proportion of their lifetime \& for constant failure rate :

$$
\text { Failure Rate } f(t)=\lambda e^{-\lambda T}[7]
$$

where $\lambda$ is No. of failures $/ 10^{6} \mathrm{hrs} \& \mathrm{~T}$ is useful life time.

\section{Data Acquisition Unit Modules}

\begin{tabular}{|l|l|l|}
\hline $\begin{array}{l}\text { S1 } \\
\text { N0. }\end{array}$ & Modules & Failures $/ 10^{6} \mathrm{hrs}$ \\
\hline 1 & Mother Board & 27.37 \\
\hline 2 & CPU & 47.05 \\
\hline 3 & Audio & 46.03 \\
\hline 4 & ARINC / Synchro & 29.38 \\
\hline 5 & Discrete & 16.98 \\
\hline 6 & Analog & 24.94 \\
\hline
\end{tabular}

Protected Memory Module

\begin{tabular}{|l|l|l|}
\hline $\begin{array}{l}\text { S1 } \\
\text { N0. }\end{array}$ & Modules & Failures $/ 10^{6} \mathrm{hrs}$ \\
\hline & & \\
\hline 1 & Memory Module & 6.172 \\
\hline
\end{tabular}

Failure Rate on System Level

\begin{tabular}{|l|l|l|}
\hline $\begin{array}{l}\text { S1 } \\
\text { N0. }\end{array}$ & Unit & Failures $/ 10^{6} \mathrm{hrs}$ \\
\hline 1 & Data Acquisition Unit & 191.75 \\
\hline 2 & Memory Module & 6.172 \\
\hline & Total & 197.922 \\
\hline
\end{tabular}

The graphical presentation of failure rate of modules is shown in Fig-4.

\section{Graphical Presentation of Failure Rate Of Modules Of Flight Data Recorder}

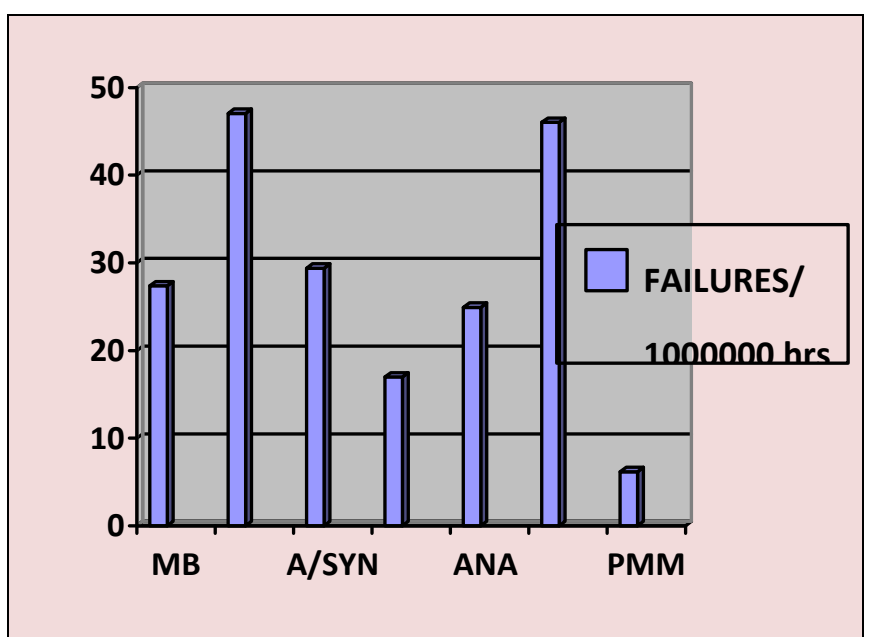

Fig-4

\section{CALCULATION OF MEAN TIME BETWEEN}

\section{FAILURE FOR RELIABILITY ANALYSIS \& PREDICTION}

Study of components / modules used in the design \& their failure rate pattern and further computation of failure rates, Reliability Prediction \& Mean Time Between Failures of the unit has been computed. The expression for Reliability $\left(\mathrm{R}_{\mathrm{T}}\right)$ is

$$
\mathrm{R}_{\mathrm{T}}=\mathrm{e}^{-\lambda \mathrm{T}}[8][9]
$$

Where

$\lambda$ is Failure Rate

$\mathrm{T}$ is Required Life

The expression for "Mean Time Between Failure" is

$$
\theta=1 / \lambda[6][10]
$$


The Mean Time Between Failure of all the modules has been calculated using the above expression. The summarized details are as follows:

\section{MTBF of Data Acquisition Unit Modules}

\begin{tabular}{|l|l|l|}
\hline $\begin{array}{l}\text { Sl } \\
\text { N0. }\end{array}$ & Modules & $\begin{array}{l}\text { Mean Time Between } \\
\text { Failure. (MTBF) Hrs }\end{array}$ \\
\hline 1 & Mother Board & 36536.35 \\
\hline 2 & CPU & 21253.99 \\
\hline 3 & Audio & 21724.96 \\
\hline 4 & ARINC / Synchro & 34036.76 \\
\hline 5 & Discrete & 58892.82 \\
\hline 6 & Analog & 40096.23 \\
\hline
\end{tabular}

MTBF of Protected Memory Module

\begin{tabular}{|l|l|l|}
\hline $\begin{array}{l}\text { Sl } \\
\text { N0. }\end{array}$ & Modules & $\begin{array}{l}\text { Mean Time Between } \\
\text { Failure. }(\text { MTBF) Hrs }\end{array}$ \\
\hline 1 & Memory Module & 162022.03 \\
\hline
\end{tabular}

The Mean Time between Failure of System is calculated using the above data. The summarized details are as follows:

MTBF of Flight Data Recorder: $5052.50 \mathrm{Hrs}$

\begin{tabular}{|l|l|l|}
\hline $\begin{array}{l}\text { Sl } \\
\text { N0. }\end{array}$ & Modules & $\begin{array}{l}\text { Mean Time Between } \\
\text { Failure. (MTBF) Hrs }\end{array}$ \\
\hline & Data Acquisition & \\
1 & Unit & 5215.12 \\
\hline 2 & Memory Module & 162022.03 \\
\hline
\end{tabular}

\section{CONCLUSION}

Mean Time between Failure of the Flight Data Recorder System is predicted as 5052.5 Hours based on the study \& analysis of the system.

The most critical modules of Data Acquisition Unit are CPU Module \& Audio Module. Hence design of these cards is critical to achieve the desired reliability.

\section{REFERENCES}

[1] MIL HDBK 217F : Reliability Prediction of Electronic Equipment, $2^{\text {nd }}$ December 1991

[2] Technical Specification of Flight Data Recorder, Issue 1.0, 12-05-2010

[3] bm.nsysu.edu.tw, A critical discussion on Bath-Tub Curve by Tan Cheng, 2013

[4] en.wikipedia.org, Bath-Tub Curve, Modified on 22/07/13

[5] www.weibull.com, The bath-Tub Curve and product failure behavior, Part One - The Bath-Tub Curve, Infant Mortality and Burn-in by Dennis J Wilkins, Issue-21, November 2002

[6] www.reliabiltyeducation.com, Reliability Prediction Basics, Copyright 2007, ITEM S/w Inc.

[7] en.wikipedia.org, Failure Rate, Modified on 25/07/2013
[8] Besterfield D.H. "Quality Control” $3^{\text {rd }}$ Edition Upper Saddle River, N.J.: Prentice Hall

[9] Amitava Mitra, "Fundamentals of Quality Control and Improvement", $2^{\text {nd }}$ Edition, 2010, PHI Learning Private Limited

[10] www.vicorpower.com, Reliability \& MTBF overview 